\title{
Five ways to enhance the impact of climate science
}

\author{
David Christian Rose \\ University of Cambridge
}

Policy-making is rarely driven by evidence alone. Thus, climate scientists who adopt an 'evidence-based' mindset, expecting more science to lead automatically to better policy, are likely to be disappointed. Instead, embracing an 'evidence-informed' attitude to policymaking will be more productive, recognising that evidence must be deployed in such a way as to interact persuasively with other factors. Using the $5^{\text {th }}$ Assessment Report of the IPCC as inspiration, this commentary argues that climate scientists would do well to consider five ideas and ultimately embrace an evidence-informed approach to presenting evidence.

\section{Introduction}

Consider the following statements:
"Anyone who needed convincing about the scale of the [climate change] problem need only have watched the recent "Panorama" programme on the floods." (Mullin, 2000 ${ }^{1}$ )
"Colleagues across the House can argue about whether [flooding] is linked to climate change or not. I very much suspect that it is" (Cameron, 2014')

Both statements comprise responses to Parliamentary questions in which ministers in the UK Government have been asked to explain recent extreme events. In both cases, flooding is clearly linked to climate change, and this reflects a wider tendency to make a connection between environmental change and the increasing frequency of extreme events. Yet, despite continuing high profile claims about the urgency and gravity of the threat of climate change, policy seems to lag behind, and climate-based disasters gradually fade from media headlines. So why does meaningful policy not result, even when policy-makers appear to accept that climate change is causing problems? Put simply, it is because policy-making is rarely 'evidence-based'.

\section{1- Reject an 'evidence-based' mindset}

It is clear that the growing confidence in climate science and observable impacts of climate change have led many policy-makers to believe that climate change is a serious issue; however, considering the lack of meaningful action on climate change, this logic does not readily translate into policy-makers believing that it is politically possible to act. Students of the policy process would not be surprised that evidence fails to influence policy in a linear fashion (rejecting figure 1 ) $^{\mathrm{ii}}$, instead finding that scientific rationality must interact alongside other factors.

\footnotetext{
${ }^{1}$ HC Deb 21 November 2000 vol 357 cc33-40WH (via Hansard Historical search)
} 


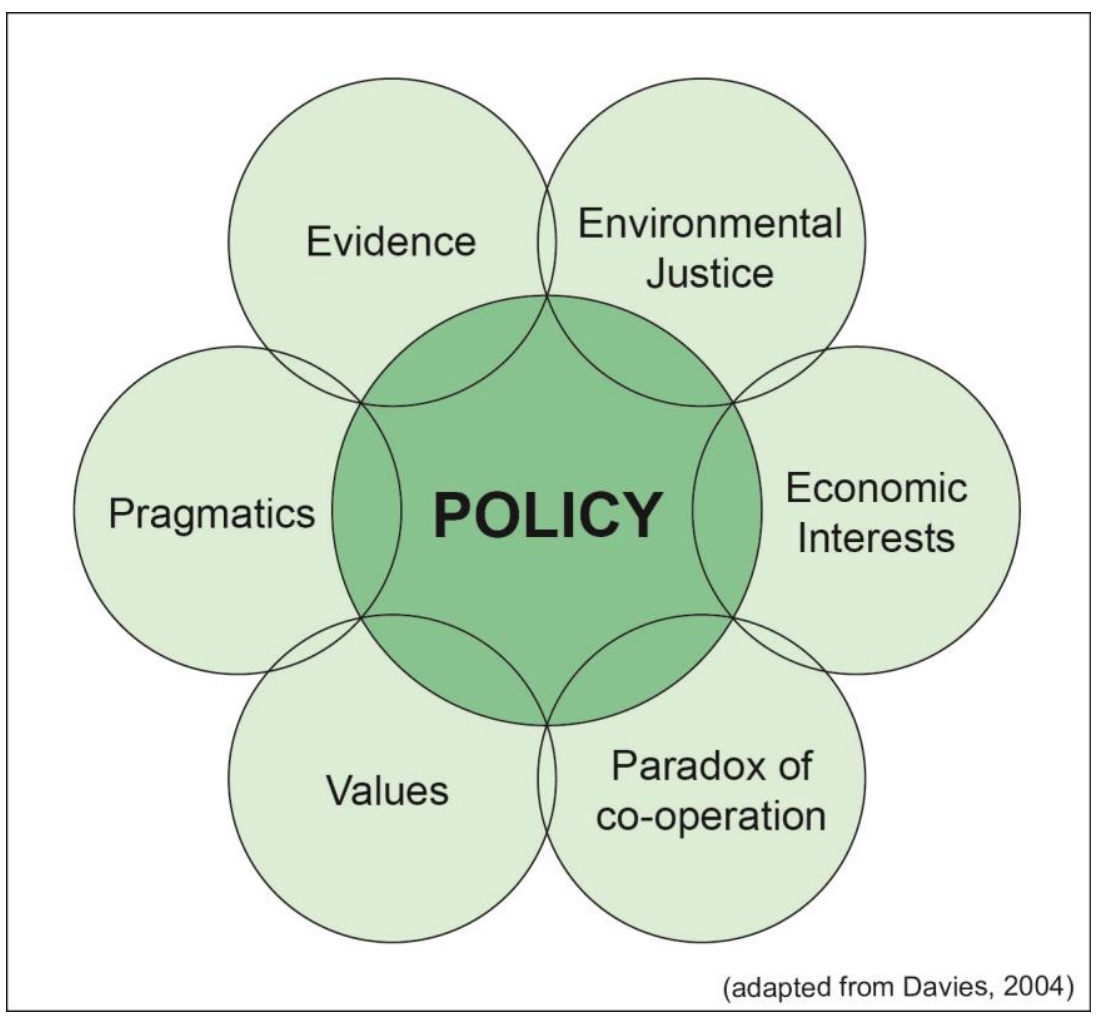

Figure 1 - Is policy usually 'based' on evidence alone? Additionally, even if evidence was the only factor in the policy-making process, this would not automatically mean that policy was made on this evidence. The evidence itself might be presented in an unpalatable way for policy-makers, thus failing to impact on policy even in the absence of other influences.

Indeed, the critical factor in Kingdon'siii analysis of Government agenda-setting refers to the influence of political conditions on scientific evidence, stating that if an idea does not fit prevailing conditions, then politics can supersede even the most pressing and well researched science. In many environmental controversies, therefore, no amount of scientific evidence can influence policy and solve problems ${ }^{\mathrm{ivv}}$, even if policy-makers understand that the evidence is convincing. Policy-making in the climate realm is no exception, with many authors finding overwhelming evidence to suggest that policy responses 'reflect $\{s\}$ a political balance of power rather than any firm direction derived from

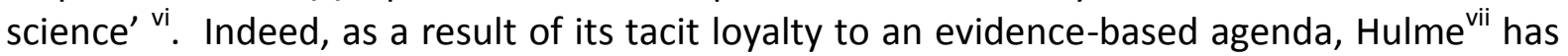
argued that the IPCC (particularly the First Working Group's focus on the physical science basis) is 'no longer fit for purpose', because a continued focus on producing 'more' science fails to understand that policy is not formulated in the way described in figure 1.

\section{2- Embrace an 'evidence-informed'viii approach}

Climate scientists could address the question posed by Schön, in which he characterises messy policy arenas as 'swampy lowlands' 
'Shall .... [the scientist] descend to the swamp...and forsake technical rigor...[and] deliberately involve himself in messy but crucially important problems?'

In climate change negotiations, progress is often hampered by competing economic interests and issues of environmental justice, not by lack of evidence; questions such as who wins? Who loses? Who decides? Whilst technical rigor remains vital, it can be productive to enter the 'swamp', seeking to understand the nature of competing interests and learning how to deploy evidence alongside these other considerations.

Solomon and Manning ${ }^{\mathrm{x}}$ might discourage the IPCC and climate scientists more widely from making such a shift, arguing that they 'must maintain...rigor' as this is the 'foundation for the most appropriate next steps in...climate policy'. However, just as foundations are useless unless something is built upon them, providing 'the facts' to policy-makers are wasted if no meaningful policy results.

\section{3- Greater certainty might not make a difference}

An overemphasis on the continued reduction of scientific uncertainty can be misguided. The IPCC's $5^{\text {th }}$ Assessment report ( $1^{\text {st }}$ Working Group) emphasised that the body was $95 \%$ certain that humans were responsible for climate change, a $5 \%$ increase from the $4^{\text {th }}$ Assessment report. Whilst it should be acknowledged that in some disciplines a 95\% confidence level would be significant (this can reject the null hypothesis), it is unwise to consider that this approach to certainty is adopted by policy-makers. So is it likely that a 95\% confidence level or more will be influential when we acknowledge that their decisions are influenced by much more than science?

To argue in the affirmative would reinforce an assessment of the policy process which is linear, arguing that more science leads to better policy. In contrast, some complex environmental controversies can never be solved by an infinite amount of science, as the prevailing conditions are not right for that evidence to be influential. Thus, if we reject this linearity, then we must also start to question the value of continuing with efforts to focus constantly on improving scientific certainty, particularly in 'wicked problems' where $100 \%$ certainty is impossible.

\section{4- Tell good news stories}

Telling good news stories is essential. Although climate change is undoubtedly serious, do climate scientists have to present doom-laden evidence much of the time? Even some climate scientists have vociferously argued that they are weary of apocalyptic discourses, exemplified by the following reaction to the Second Working Group report within the IPCC's Fifth Assessment:

"The message in the first draft was that... these were manageable risks...This has completely disappeared from the [final] draft... which is all about the impacts of climate change and the four horsemen of the apocalypse." (Tol, 2014 ${ }^{\mathrm{xi}}$ ) 
Whilst the wider media reaction to the report of the Second Working Group generally recognised a shift towards a position which argued that adaptation to climate was possible, the public withdrawal of Professor Tol from the report indicates that an opportunity was missed to create a pervasive positive narrative. There is plenty of evidence that telling 'good news' stories works. Flyvbjerg ${ }^{\mathrm{xii}}$, for example, shows that policy-makers often like to see something 'work' on the ground before they consider whether to enact policy, and other disciplines have illustrated the value of communicating success stories ${ }^{\text {xiii. }}$

So where are all the climate success stories? In making this point, I do not imply that there are few examples of effective climate action, instead arguing that there should be greater communication of successful projects. Currently, from the point of view of someone who conducts research in climate science, I struggle to think instantly of a range of examples where there have been successful climate interventions. Thus, it would be useful if success stories were highlighted more in climate reports so that references to these examples could be commonplace, acting as a model for best practice. Climate scientists would do well to extend the sentiment that was present at times within the Second Working Group report (that adaptation is possible), showing those policy-makers who aren't currently making meaningful climate change policies that action on climate change can work.

\section{5- 'Re-frame' climate science in a policy relevant way}

Attaching the project to a politically salient issue has increased the influence of many ideas amongst policy-makers; for example, 'ecosystem services' in nature conservation can show that doing the right thing for nature doesn't necessarily mean doing the worst thing for the economy (perhaps a Faustian bargain, nevertheless). A useful example of astute framing of evidence can be viewed by analyzing the campaign of the Royal Society for the Protection of Birds (RSPB) against the trade in wild birds. The RSPB was able to 're-frame' their evidence against wild bird trading when they sensed an opportunity to package it in a politically salient way. They had campaigned for a long period of time to achieve an EU ban, presenting clear evidence that the trade was ongoing. Initially, this evidence was framed on animal welfare grounds, but this line of argument failed to impact on policy. However, when the bird flu crisis struck, the RSPB were able to show that the trade in wild birds was a serious issue for human health, potentially providing an avenue for spreading the disease further. This salient framing of the same evidence had an immediate influence on policy ${ }^{\mathrm{xiv}}$.

Where possible, climate science should be communicated in a policy relevant way (the IPCC is meant to be 'policy relevant' after all), showing that doing the right thing for climate is not always alien to other priorities. Of course, this won't always be possible, but climate scientists can productively seek a better understanding of current political priorities, and consequently package their evidence in a more influential way.

\section{Conclusion}

This commentary has argued that when presenting climate science to policy-makers it is rarely adequate for evidence to be merely 'correct'; it must also be persuasive. And thus, climate scientists would do well to pay more attention to understanding how policy negotiations work, what could be done to ameliorate differences between decision-makers, and how science could be presented in persuasive form. Because, at times, researchers 'are 
informing battles' but are often 'not providing the knowledge needed...to win the war' and thus they must start to work 'outside \{their\} comfort zone ${ }^{\prime x \mathrm{v}}$.

The battle to protect the world from climate change will not be won by firing a single canon repeatedly at decision-makers loaded with a slightly larger cannonball each time proving that humans are responsible for climate change or expecting extreme climate events to convince policy-makers to take sudden action. Rather the battle may be won by firing a broadside shot at policy-makers, which is loaded with targeted information about how policy systems work, which issues are particularly prominent in holding up meaningful action and then frame evidence accordingly, and lastly practical solutions to overcome them. In directing these efforts wisely, climate scientists can win battles. Otherwise, in several years times policy-makers might again be vociferously blaming another extreme event on climate change and leave climate scientists wondering why little attention was paid to the accumulating evidence.

\section{Acknowledgements}

This work (including quotes designated as 'in interview') is taken from a larger PhD project currently being undertaken in the Department of Geography at the University of Cambridge. This work is very kindly funded by the Economic and Social Research Council (grant number ES/I901957/1) and by the Homerton College Charter Scholarship scheme. I would like to thank Professor S.E. Owens, Dr A. Donovan and Professor W. Adams for their valued comments on a previous draft of this paper.

\footnotetext{
' Mason, R. 2004. David Cameron 'very much suspects' climate change is behind recent storms, available April 2014 at: http://www.theguardian.com/politics/2014/jan/08/cameron-suspects-climatechange-abnormal-storms

ii Owens, S., 2012. Experts and the environment: the UK Royal Commission on Environmental Pollution 1970-2011, Journal of Environmental Law 24: 1-22

iii Kingdon, J., 2003. Agendas, Alternatives, and Public Policies, 2nd Edition, Longman, New York, USA

iv Pielke Jr., R. A., 2004. When scientists politicize science: making sense of controversy over The Skeptical Environmentalist, Environmental Science \& Policy 7: 405-417

${ }^{\vee}$ Sarewitz, D. 2004. How science makes environmental controversies worse, Environmental Science and Policy 7: 385-403

${ }^{v i}$ Bohmer- Christiansen, S., 1994. Global Climate Protection Policy: the limits of scientific advice, Part 2, Global Environmental Change 4 (2): 185-200 (quote page 192)

vii Hulme, M. 2010. IPCC: Cherish it, tweak it or scrap it? Nature 463:730-731

viii Sandbrook, C. and Adams, W. M., 2013. Conservation, Evidence and Policy, Oryx 47 (3): 329-335

${ }^{\text {ix }}$ Schön, D.A. 1983. The Reflective Practitioner, Basic Books, New York (quote page 42-43)

${ }^{x}$ Solomon, S. and Manning, M. 2008. The IPCC Must Maintain Its Rigor, Science 319 (5869): 1457 (quote page 1457)
} 
xi Shukman, D. 2014. Dissent among scientists over key climate impact report, available April 2014 at: http://www.bbc.co.uk/news/science-environment-26655779

xii Flyvbjerg, B. 2004. Phronetic Planning Research: Theoretical and Methodological Reflections, Planning Theory and Practice 5 (3): 283-306

xiii Balmford, A., 2012. Wild Hope: On the Front Lines of Conservation Success, The University of Chicago Press, Chicago and London

xiv Avery, M. 2012. Fighting for Birds: 25 years in nature conservation, Pelagic Publishing, Exeter, United Kingdom

xv Andelman, S. J. 2011. Conservation science outside the comfort zones, Nature 475: 290-291 (quote page 290-291)

Figure $1^{x v}$ - Is policy usually 'based' on evidence alone? Additionally, even if evidence was the only factor in the policy-making process, this would not automatically mean that policy was made on this evidence. The evidence itself might be presented in an unpalatable way for policy-makers, thus failing to impact on policy even in the absence of other influences. 